\title{
Cholinesterase Inhibitors Ameliorate Behavioral Deficits Induced by MK-80I in Mice
}

\author{
John G Csernansky*, ,,2, Maureen Martin ',3, Renu Shah', Amy Bertchume', Jenny Colvin' and Hongxin Dong' \\ 'Department of Psychiatry, Washington University School of Medicine, St Louis, MO, USA; 'Department of Anatomy and Neurobiology, \\ Washington University School of Medicine, St Louis, MO, USA; ${ }^{3}$ Department of Psychology, St Louis University, St Louis, MO, USA
}

\begin{abstract}
Enhancing cholinergic function has been suggested as a possible strategy for ameliorating the cognitive deficits of schizophrenia. The purpose of this study was to examine the effects of acetylcholinesterase (AChE) inhibitors in mice treated with the noncompetitive $\mathrm{N}$ methyl-d-aspartate (NMDA) receptor antagonist, MK-80I, which has been suggested as an animal model of the cognitive deficits of schizophrenia. Three separate experiments were conducted to test the effects of physostigmine, donepezil, or galantamine on deficits in learning and memory induced by MK-80 I. In each experiment, MK-80I $(0.05$ or $0.10 \mathrm{mg} / \mathrm{kg})$ or saline was administered i.p. 20 min prior to behavioral testing over a total of 12 days. At 30 min prior to administration of MK-80 I or saline, one of three doses of the AChE inhibitor (ie physostigmine - 0.03, 0.10, or $0.30 \mathrm{mg} / \mathrm{kg}$; donepezil-0.10,0.30, or $1.00 \mathrm{mg} / \mathrm{kg}$; or galantamine - $0.25,0.50$, or $1.00 \mathrm{mg} / \mathrm{kg}$ ) or saline was administered s.c. Behavioral testing was performed in all experimental animals using the following sequence: ( 1 ) spatial reversal learning, (2) locomotion, (3) fear conditioning, and (4) shock sensitivity. Both doses of MK-80I produced impairments in spatial reversal learning and in contextual and cued memory, as well as hyperlocomotion. Physostigmine and donepezil, but not galantamine, ameliorated MK-80I-induced deficits in spatial reversal learning and in contextual and cued memory in a dose-dependent manner. Also, physostigmine, but not donepezil or galantamine, reversed MK-80 I-induced hyperlocomotion. Galantamine, but not physostigmine or donepezil, altered shock sensitivity. These results suggest that AChE inhibitors may differ in their capacity to ameliorate learning and memory deficits produced by MK-80I in mice, which may have relevance for the cognitive effects of cholinomimetic drugs in patients with schizophrenia.
\end{abstract}

Neuropsychopharmacology (2005) 30, 2 I35-2 I 43. doi:I 0.1038/sj.npp. I 30076I; published online 8 June 2005

Keywords: fear conditioning; reversal learning; schizophrenia; acetylcholinesterase inhibitors; MK-80 I

\section{INTRODUCTION}

There has been increasing interest in developing new drug treatments for the cognitive deficits of schizophrenia (Fenton et al, 2003), and among the CNS targets for such treatments is the cholinergic neurotransmitter system (Friedman, 2004). The cholinergic system projects widely throughout the brain, and includes dense projections to limbic and paralimbic areas (Mesulam and Geula, 1988). Pharmacological studies have shown that muscarinic antagonists, such as scopolamine, can produce memory deficits in rodents and primates (Aigner and Mishkin, 1986; Rogers and Kesner, 2003, 2004). Also, acetylcholinesterase (AChE) inhibitors have been shown to reverse the memory deficits induced by such drugs (Higgins et al, 2002; Ballard

\footnotetext{
*Correspondence: Dr JG Csernansky, Department of Psychiatry (Box 8134), Washington University School of Medicine, 660 S. Euclid, St Louis, MO 63।I0, USA, Tel: + I 314747 2160, Fax: + I 314747 2182, E-mail: jgc@conte.wustl.edu

Received I4 December 2004; revised and accepted I April 2005 Online publication: 4 April 2005 at http://www.acnp.org/citations/ Npp040405040588/default.pdf
}

and McAllister, 1999; Rupniak et al, 1997). Acetylcholine levels are increased in the hippocampus and cortex during cognitive processes in rats (Pepeu and Giovannini, 2004) and decreases in CSF acetylcholine concentrations are correlated with cognitive decline in Alzheimer's disease (Jian-ping et al, 2004).

AChE inhibitors are now routinely used for the treatment of dementia in patients with probable Alzheimer's disease (Knopman and Morris, 1997), and among such drugs, donepezil (Rogers et al, 1996) and galantamine (Raskind et al, 2000) are among the most widely prescribed in the United States. AChE inhibitors have also been tested for their capacity to ameliorate the cognitive deficits associated with schizophrenia, but with less than definitive results (Tugal et al, 2004; Buchanan et al, 2002; Lenzi et al, 2003).

The purpose of this study was to examine the effects of AChE inhibitors in mice treated with the noncompetitive $\mathrm{N}$ methyl-d-aspartate (NMDA) receptor antagonist, MK-801, which has been suggested as an animal model of the cognitive deficits of schizophrenia (Bardgett et al, 2003). Several recent hypotheses about the pathophysiology of schizophrenia have implicated NMDA-type glutamate 
receptors (Olney and Farber, 1995; Goff and Coyle, 2001; Coyle and Tsai, 2004). Early support for such hypotheses came from observations that the noncompetitive NMDA receptor antagonist, phencyclidine (PCP), induced a psychosis similar to that observed in patients with schizophrenia (Luisada and Brown, 1976; Allen and Young, 1978). More recently, other noncompetitive NMDA receptor antagonists, such as ketamine and MK-801, have been shown to produce complex syndromes that mimic positive and negative symptoms, as well as the cognitive deficits of schizophrenia (Adler et al, 1999; Buffalo et al, 1994; Moghaddam and Jackson, 2003; Newcomer and Krystal, 2001). Notably, antipsychotic drugs used in the treatment of schizophrenia, such as haloperidol, risperidone, and clozapine, have been shown to block the hyperlocomotion, stereotypies, and ataxia induced by MK-801 in rats (Andine et al, 1999); however, the effects of such drugs on the learning and memory deficits induced by MK-801 in rodents (Bardgett et al, 2003) has not been investigated.

The rationale for using $\mathrm{AChE}$ inhibitors to ameliorate cognitive deficits in mice induced by NMDA receptor blockade can be based on neuroanatomical and functional interactions between CNS cholinergic and glutamatergic systems (Everitt and Robbins, 1997). The tri-synaptic excitatory circuit within the hippocampus receives tonic excitatory cholinergic input from the medial septum and the diagonal band of Broca (Benes, 1999; Colgin et al, 2003; Stewart and Fox, 1990). In turn, glutamate, acting on NMDA receptors located on inhibitory GABAergic interneurons within the septum, inhibits the activity of cholinergic neurons that project to the hippocampus (Giovannini et al, 1994). Muscarinic drugs, including both muscarinic (Friedman, 2004) and nicotinic agonists (Martin et al, 2004) have been investigated for their cognition enhancing effects in a number of animal species. Also, post-mortem studies of the brains of subjects with schizophrenia provide support for the hypothesis that abnormalities of the cholinergic system may underlie at least some of the cognitive deficits associated with schizophrenia (Freedman et al, 1995; Friedman, 2004; Hyde and Crook, 2001).

In the present study, groups of mice were pretreated with multiple doses of physostigmine, donepezil, and galantamine prior to administration of the noncompetitive NMDA antagonist, MK-801. Behaviors related to learning and memory were assessed using T-maze reversal learning and fear-conditioning paradigms (Bardgett et al, 2003). Physostigmine was selected for this study because it is considered the prototypical AChE inhibitor (Knopman and Morris, 1997), while donepezil and galantamine were selected because they are frequently used in the treatment of patients with Alzheimer disease and are being considered for use in patients with schizophrenia (Tugal et al, 2004; Buchanan et al, 2002; Lenzi et al, 2003). Moreover, while all three drugs inhibit AChE, they differ in their capacity to modulate nicotinic acetylcholine receptors (Samochocki et al, 2003).

\section{METHODS}

Animals and housing: A total of 404 male C57BL/6Hsd mice (10-12 animals per experiment condition) (Jackson Laboratories, Bar Harbor, Maine), 7 weeks of age, were used for all experiments. The animals were housed in groups of 3 or 4 , and food and water were available ad libitum. All procedures were performed according to NIH guidelines for the treatment of animal subjects and the Current Guide for the Care and Use of Laboratory Animals (USPHS) under a protocol approved by the Washington University Animal Studies Committee. Care was taken to minimize the pain, suffering, and number of animals used.

Drug administration: The animals were divided into three approximately equal groups to conduct separate experiments to test the effects of physostigmine, donepezil or galantamine on behavioral deficits induce by MK-801. In each experiment, MK-801 (RBI, Natick, MA), at doses of 0.05 or $0.10 \mathrm{mg} / \mathrm{kg}$, or saline was administered by intraperitoneal (i.p.) injection. At $30 \mathrm{~min}$ prior to administration of MK-801 or saline, one of three doses of the AChE inhibitor (ie physostigmine salicylate (Sigma, St Louis), donepezil (Eisai Co. Ltd, Tokyo, Japan) or galantamine (Sigma, St Louis)) or saline was administered subcutaneously. Three doses of each drug were tested: that is, physostigmine $(0.03,0.10$, or $0.30 \mathrm{mg} / \mathrm{kg})$, donepezil $(0.10$, 0.30 , or $1.00 \mathrm{mg} / \mathrm{kg}$ ), and galantamine $(0.25,0.50$, or $1.00 \mathrm{mg} /$ $\mathrm{kg}$ ). All drugs were administered in a constant volume of $1 \mathrm{ml} / \mathrm{kg}$ of body weight. Behavioral testing was performed $50 \mathrm{~min}$ after AChE inhibitor pretreatment and $20 \mathrm{~min}$ after administration of $\mathrm{MK}-801$ or saline.

The doses of MK- 801 and the timing of MK-801 dosing prior to behavioral testing was based on previous studies utilizing the same behavioral paradigms in our laboratory (Bardgett et al, 2003). Drug doses and the timing of dosing prior to MK-801 administration and behavioral testing for physostigmine (Ohno et al, 1996), donepezil (Wang and Tang, 1998), and galantamine (Barnes et al, 2000) were similarly based on prior studies of these drugs in rodents. Also, the maximal doses of each of the three AChE inhibitors were tested in preliminary experiments to exclude the possibility that they invalidate the behavioral paradigms used.

\section{Behavioral and Cognitive Testing}

Behavioral testing was performed in all experimental animals using the following sequence: (1) spatial reversal learning, (2) locomotion, (3) fear conditioning, and (4) shock sensitivity over a total of 14 days. This sequence of testing was not randomized, but was determined instead to minimize interference of the testing procedures across the four paradigms, as previously described (Bardgett et al, 2003). Locomotion and shock sensitivity testing followed spatial reversal learning and fear-conditioning testing, respectively, as control conditions. Drug administration was administered in an identical manner on each day of behavioral testing.

Spatial reversal learning: Spatial reversal learning was assessed on days 1-5 using a water T-maze. A four-armed maze was constructed of $1-\mathrm{cm}$ thick clear Plexiglas; each arm was $21.5 \mathrm{~cm}$ long, $10.5 \mathrm{~cm}$ wide, and $34.5 \mathrm{~cm}$ deep. One of the arms was blocked to create a ' $\mathrm{T}$ ' configuration, and an 8.8 by $8.8 \mathrm{~cm}$ rectangular platform was placed at the end of the target arm. Warm water made opaque with nontoxic white paint was added to the maze to conceal the platform submerged $0.5 \mathrm{~cm}$ below the surface. 
The animals were habituated to the apparatus on days 1-3 by placing them in the water near the platform and allowing them to climb onto the platform. Once the animals were able to climb onto the platform in less than $10 \mathrm{~s}$, they were repeatedly placed at the entrance of the T-maze until they successfully located and climbed onto the platform six times. Then, the platform was moved to the opposite arm and testing was repeated until the animals again located and climbed onto the platform six times.

On day 4, the platform was placed either in the right or the left arm for all trials (animals in each group were equally distributed between the two sides), and the animals were tested until they successfully located the platform six out of eight times; the number of trials required until each animals met this criterion was recorded. On day 5, the location of the platform was reversed to the other side of the T-maze, and the number of trials required until each animal successfully located the platform six out of eight times (ie reversal learning) was again recorded.

Locomotor activity: Locomotor activity was tested on day 6 for a period of $60 \mathrm{~min}$ as previously described (Bardgett et al, 2003). Animals were tested in clear polycarbonate cages ( $46 \mathrm{~cm}$ long, $25.5 \mathrm{~cm}$ wide, and $21.5 \mathrm{~cm}$ high) within a darkened room. Locomotor activity was assessed by counting the number of times animals interrupted 12 beams of red light evenly spaced along the length and width of the activity cage. The total number of beam breaks that occurred during the testing period was recorded.

Fear conditioning: The assessment of contextual and cued memory within a fear-conditioning paradigm was performed on days 7-9 again using methods previously described (Bardgett et al, 2003). Animals were trained and tested in two Plexiglas conditioning chambers (Med Associates, Inc., Georgia, VT). The chambers were $26 \mathrm{~cm}$ long, $18 \mathrm{~cm}$ high, and $18 \mathrm{~cm}$ wide, with a metal grid floor, and were contained within a larger sound-attenuating chamber with a $24-\mathrm{W}$ white light and a fan to provide $75 \mathrm{~dB}$ background noise.

On day 7, training took place in the first chamber, which contained a cup containing mint extract beneath the grid floor. The animals were acclimated to the chamber for $5 \mathrm{~min}$, and freezing behavior, defined as no movement (ambulation, sniffing, or stereotypy) other than respiration, was recorded every $10 \mathrm{~s}$. After $2 \mathrm{~min}$, a $20 \mathrm{~s}, 80 \mathrm{~dB}, 2800 \mathrm{~Hz}$ tone was presented, and during the last $2 \mathrm{~s}$ of the tone, the animals received a $1.0 \mathrm{~mA}$ continuous footshock. This procedure was repeated two more times at 1-min intervals.

On day 8 , the amount of freezing behavior in response to context (ie memory for context) was tested by returning the animals to the first chamber (scented with mint) and recording freezing behavior again every $10 \mathrm{~s}$ for $8 \mathrm{~min}$. On day 9 , the animals were placed in a second chamber scented with coconut and in which the grid floor was covered with a sheet of smooth polyurethane. Freezing behavior was again recorded for $2 \mathrm{~min}$, and then the $80 \mathrm{~dB}, 2800 \mathrm{~Hz}$ tone was represented continuously for $8 \mathrm{~min}$; freezing behavior in response to the cue (ie memory for cue) was recorded.

Footshock sensitivity: Sensitivity to the footshock administered during the fear-conditioning paradigm was tested on day 10 . The animals were returned to the first conditioning chamber for $2 \mathrm{~min}$ and exposed to a series of $2-s$ shocks, beginning with an intensity of $1.0 \mathrm{~mA}$. The shock intensity was increased by $0.5 \mathrm{~mA}$ every $20-30 \mathrm{~s}$ until a jumping response was evoked.

\section{Data Analysis}

In the spatial reversal learning paradigm, the number of trials required to reach criterion (six of eight successful trials) for acquisition of the task and reversal learning were used in data analyses. In the fear-conditioning paradigm, the percent of time spent freezing during the period of exposure to context, altered context, and cue were used in data analyses. The number of light beam interruptions over $60 \mathrm{~min}$ and the amperage necessary to elicit a jumping response were used as measures of locomotion and shock sensitivity, respectively, in data analyses. Data analyses were conducted separately for each drug treatment and each behavioral paradigm using two-way ANOVA and MK-801 dose groups and AChE inhibitor dose groups as factors. Post hoc analyses were conducted using Fisher's PLSD test.

\section{RESULTS}

\section{MK-801 Effects on Behavior}

The capacity of the three AChE inhibitors, physostigmine, donepezil, and galantamine, to reverse the behavioral effects of MK-801 was studied in Experiments 1, 2, and 3, respectively. Across all three experiments, MK-801 generally produced the predicted effects on behavior. In all three experiments, MK-801 significantly increased the numbers of trials required to acquire the spatial learning task (Experiment $1-\mathrm{F}=18.3, \quad \mathrm{df}=2,132, \quad p<0.0001$; Experiment $2-\mathrm{F}=42.2, \mathrm{df}=2,132, p<0.0001$; Experiment $3-\mathrm{F}=6.4$, $\mathrm{df}=2,104, p=0.002$ ). Also, in two of three experiments, MK-801 significantly increased the numbers of trials required for reversal learning (Experiment $1-\mathrm{F}=15.9$, $\mathrm{df}=2,132, p<0.0001$; Experiment $2-\mathrm{F}=49.1, \mathrm{df}=2,132$, $p<0.0001$; Experiment $3-\mathrm{F}=2.5, \mathrm{df}=2,104, p=0.08$ ). Notably, there were also significant MK-801-induced increases in locomotion (Experiment $1-\mathrm{F}=46.0$, $\mathrm{df}=2,130, p<0.0001$; Experiment $2-\mathrm{F}=15.9, \mathrm{df}=2,129$, $p<0.0001$; Experiment $3-\mathrm{F}=19.0, \mathrm{df}=2,85, p<0.0001$ ).

In all three experiments, MK-801 significantly decreased the amount of freezing behavior in response to context (Experiment $1-\mathrm{F}=52.6, \mathrm{df}=2,132, p<0.0001$; Experiment $2-\mathrm{F}=106.4, \quad \mathrm{df}=2,132, \quad p<0.0001 ; \quad$ Experiment $3-\mathrm{F}=59.2, \mathrm{df}=2,104, p<0.0001$ ), altered context (Experiment $1-\mathrm{F}=24.3, \quad \mathrm{df}=2,132, \quad p<0.0001$; Experiment $2-\mathrm{F}=32.9, \mathrm{df}=2,132, p<0.0001$; Experiment $3-\mathrm{F}=9.5$, 2,104, $p=0.0002$ ), and cue (Experiment $1-\mathrm{F}=43.7$, $\mathrm{df}=2,132, p<0.0001$; Experiment $2-\mathrm{F}=41.9, \mathrm{df}=2,132$, $p<0.0001$; Experiment $3-\mathrm{F}=43.0, \mathrm{df}=2,104, p<0.0001$ ). In two of three experiments, MK-801 did not significantly alter footshock sensitivity (Experiment $1-\mathrm{F}=1.3$, $\mathrm{df}=2,132, \quad p=0.29 ; \quad$ Experiment $2-\mathrm{F}=0.2, \mathrm{df}=2,132$, $p=0.80$; Experiment $3-\mathrm{F}=8.2, \mathrm{df}=2,104, p=0.001$ ).

\section{Experiment 1 - Physostigmine}

The effects of physostigmine on MK-801-induced impairments in behavior are summarized in Figure 1. Physostigmine significantly decreased the number of trials required 
to acquire the spatial learning task (physostigmine effect $-\mathrm{F}=12.1, \mathrm{df}=2,132, p<0.0001$ ), and reversed the increases in the number of trials required to acquire the spatial learning task that had been produced by MK-801 (interaction between physostigmine and $\mathrm{MK}-801-\mathrm{F}=4.6$, $\mathrm{df}=2,132, \quad p=0.0003)$. Physostigmine also significantly decreased the number of trials needed for reversal learning (physostigmine effect $-\mathrm{F}=10.0, \mathrm{df}=2,132, \quad p<0.0001$ ), and reversed MK-801-induced increases in the number of trials needed for reversal learning (interaction between physostigmine and $\mathrm{MK}-801-\mathrm{F}=3.8, \mathrm{df}=2,132, p=0.002$ ). Physostigmine also decreased locomotion (effect of physostigmine $-\mathrm{F}=12.4, \quad \mathrm{df}=2,130, \quad p<0.0001), \quad$ and reversed MK-801-induced hyperlocomotion (interaction between physostigmine and $\mathrm{MK}-801-\mathrm{F}=3.0, \mathrm{df}=2,130$, $p=0.008)$.

Physostigmine significantly increased the amount of freezing behavior in response to context (physostigmine effect $-\mathrm{F}=19.8, \mathrm{df}=2,132, p<0.0001$ ), and reversed decreases in the amount of freezing behavior in response to context that had been produced by MK-801 (interaction between physostigmine and $\mathrm{MK}-801-\mathrm{F}=3.1, \mathrm{df}=2,132$, $p=0.007)$. Physostigmine also significantly increased the amount of freezing behavior in response to altered context (physostigmine effect-F=44.3, $\mathrm{df}=2,132, \quad p<0.0001$ ), and reversed MK-801-induced decreases in the amount of freezing behavior in response to altered context (interaction between physostigmine and $\mathrm{MK}-801-\mathrm{F}=2.9, \mathrm{df}=2,132$, $p=0.001$ ). Finally, physostigmine increased the amount of freezing behavior in response to cue (effect of physostigmine $-\mathrm{F}=74.7, \mathrm{df}=2,132, p<0.0001$ ), and reversed MK-801-induced decreases in the amount of freezing behavior in response to cue (interaction between physostigmine and $\mathrm{MK}-801-\mathrm{F}=3.0, \mathrm{df}=2,132, \quad p=0.009$ ).
Physostigmine did not have a significant effect on shock sensitivity (physostigmine effect $-\mathrm{F}=0.9, \quad \mathrm{df}=2,132$, $p=0.44)$.

\section{Experiment 2-Donepezil}

The effects of donepezil on MK-801-induced impairments in behavior are summarized in Figure 2. Donepezil significantly decreased the number of trials required to acquire the spatial learning task (donepezil effect$\mathrm{F}=16.3, \mathrm{df}=2,131, p<0.0001)$, and reversed increases in the number of trials required to acquire the spatial learning task that had been produced by MK-801 (interaction between donepezil and $\mathrm{MK}-801-\mathrm{F}=5.1, \mathrm{df}=2,131$, $p<0.0001)$. Donepezil also significantly decreased the number of trials required for reversal learning (donepezil effect $-\mathrm{F}=14.0, \mathrm{df}=2,131, p<0.0001$ ), and reversed MK801 -induced increases in the number of trials required for reversal learning (interaction between donepezil and MK$801-\mathrm{F}=3.0, \mathrm{df}=2,131, p=0.009$ ). Donepezil did not have a significant effect on locomotion (effect of donepezil$\mathrm{F}=0.9, \mathrm{df}=2,129, p=0.45)$, nor did it reverse MK-801induced hyperlocomotion (interaction between donepezil and $\mathrm{MK}-801-\mathrm{F}=1.1, \mathrm{df}=2,129, p=0.34)$.

Donepezil significantly increased the amount of freezing behavior in response to context (donepezil effect $-\mathrm{F}=28.0$, $\mathrm{df}=2,132, \quad p<0.0001$ ), and reversed decreases in the amount of freezing behavior in response to context that had been produced by MK-801 (interaction between donepezil and $\mathrm{MK}-801-\mathrm{F}=8.7, \mathrm{df}=2,132, p<0.0001$ ). Donepezil also significantly increased the amount of freezing behavior in response to altered context (donepezil effect $-\mathrm{F}=24.4, \mathrm{df}=2,132, p<0.0001$ ), and reversed MK801 -induced decreases in the amount of freezing behavior
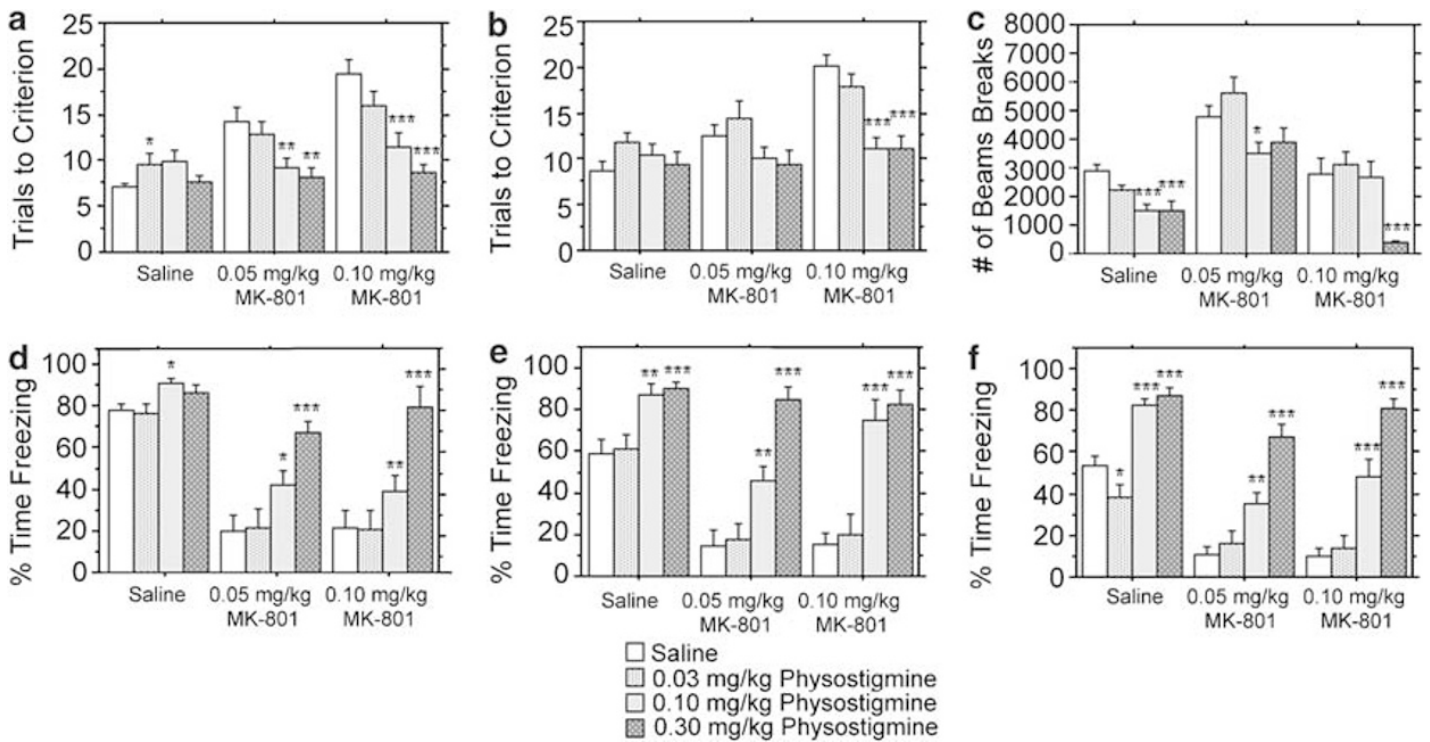

Figure I Effects of physostigmine on changes in behavior induced by MK-80I in mice. One of three doses of physostigmine were administered (s.c.) prior to administration of one of two doses of MK-80I in separate groups of mice ( $n=10-12$ per experimental group). Each panel represents the results of a different behavioral measure; that is, panel (a), the number of trials required for acquisition of a spatial learning task; panel (b), the number of trials required for reversal learning; panel (c), spontaneous locomotion; panel (d), freezing behavior in response to context; panel (e), freezing behavior in response to altered context, and panel $(f)$, freezing behavior in response to cue used. See the narrative for ANOVA results. Significant differences between individual groups pretreated with one of the three doses of physostigmine prior to administration of saline or one of two doses of MK-80I as compared to the groups pretreated with saline prior to administration of saline or one of two doses of MK-80I are denoted by $* p<0.05$, $* *$ * $<0.0$ I, or $* * * p<0.00$ I. 

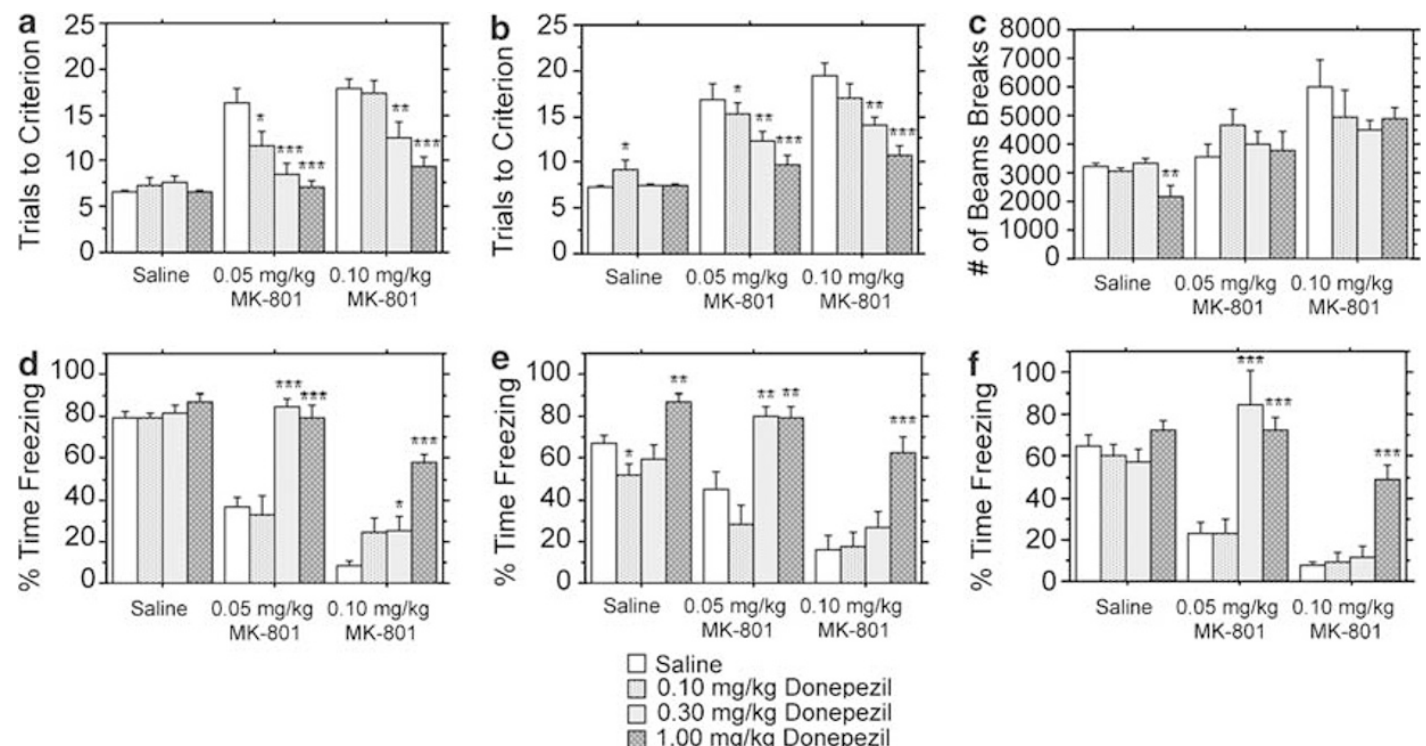

Figure 2 Effects of donepezil on changes in behavior induced by MK-80I in mice. One of three doses of donepezil were administered (s.c.) prior to administration of one of two doses of MK-80I in separate groups of mice ( $n=10-12$ per experimental group). Each panel represents the results of a different behavioral measure (see Figure I legend for panel descriptions). See the narrative for ANOVA results. Significant differences between individual groups pretreated with one of the three doses of donepezil prior to administration of saline or one of two doses of MK-80I as compared to the groups pretreated with saline prior to administration of saline or one of two doses of MK-80 I are denoted by $* p<0.05$, *** $<<0.0$ I, or $* * * p<0.00$ I.

in response to altered context (interaction between donepezil and $\mathrm{MK}-801-\mathrm{F}=3.5, \mathrm{df}=2,132, p=0.003)$. Finally, donepezil increased the amount of freezing behavior in response to cue (effect of donepezil $-\mathrm{F}=15.9, \mathrm{df}=2,132$, $p<0.0001)$, and reversed MK-801-induced decreases in the amount of freezing behavior in response to cue (interaction between donepezil and $\mathrm{MK}-801-\mathrm{F}=7.0, \mathrm{df}=2,132$, $p<0.0001)$. Donepezil did not have a significant effect on shock sensitivity (donepezil effect $-\mathrm{F}=2.6, \mathrm{df}=2,132$, $p=0.054)$.

\section{Experiment 3-Galantamine}

The effects of galantamine on MK-801-induced impairments in behavior are summarized in Figure 3. Galantamine did not significantly change the number of trials required to acquire the spatial learning task (galantamine effect $-\mathrm{F}=1.5, \mathrm{df}=2,104, p=0.21$ ), nor did it reverse increases in the number of trials required to acquire the spatial learning task that had been produced by MK-801 (interaction between galantamine and $\mathrm{MK}-801-\mathrm{F}=0.9$, $\mathrm{df}=2,104, p=0.51)$. Galantamine also did not significantly change the number of trials required for reversal learning (galantamine effect $-\mathrm{F}=2.0, \mathrm{df}=2,104, p=0.11$ ), nor did it reverse MK-801-induced increases in the number of trials required for reversal learning (interaction between galantamine and $\mathrm{MK}-801-\mathrm{F}=0.9, \mathrm{df}=2,104, p=0.52$ ). Galantamine produced a significant increase in locomotion (effect of galantamine- $-\mathrm{F}=3.7, \mathrm{df}=2,85, p=0.01$ ), and accentuated MK-801-induced hyperlocomotion (interaction between galantamine and $\mathrm{MK}-801-\mathrm{F}=5.1, \mathrm{df}=2,85$, $p=0.0002$ ).

Galantamine did not significantly change the amount of freezing behavior in response to context (galantamine effect $-\mathrm{F}=1.1, \mathrm{df}=2,104, p=0.36$ ), but did tend to reverse the decreases in the amount of freezing behavior in response to context that had been produced by MK- 801 (interaction between galantamine and $\mathrm{MK}-801-\mathrm{F}=2.2$, $\mathrm{df}=2,104, p=0.04)$. Similarly, galantamine did not significantly change the amount of freezing behavior in response to altered context (galantamine effect $-\mathrm{F}=2.5$, $\mathrm{df}=2,104, \quad p=0.06$ ), but did reverse MK-801-induced decreases in the amount of freezing behavior in response to altered context (interaction between galantamine and MK-801 $-\mathrm{F}=3.2, \mathrm{df}=2,104, p=0.006$ ). Finally, galantamine decreased the amount of freezing behavior in response to cue (effect of galantamine $-\mathrm{F}=5.7, \mathrm{df}=2,104, p=0.001$ ) (see Figure 3, panel f), and did not reverse decreases in freezing behavior in response to cue that had been produced by MK-801 (interaction between galantamine and $\mathrm{MK}-801-\mathrm{F}=1.3, \mathrm{df}=2,104, p=0.28)$. Galantamine also decreased shock sensitivity (galantamine effect$\mathrm{F}=11.6, \mathrm{df}=2,104, \quad p<0.0001)$, and reversed MK-801induced increases in shock sensitivity that were observed in this experiment (interaction between galantamine and $\mathrm{MK}-801-\mathrm{F}=4.0, \mathrm{df}=2,104, p=0.001)$.

\section{DISCUSSION}

The results of this study suggest that physostigmine and donepezil, but not galantamine, can ameliorate deficits in learning and memory produced by the NMDA antagonist, MK-801, in mice. Both doses of MK-801 $(0.05$ and $0.10 \mathrm{mg} /$ $\mathrm{kg}$ ) produced the expected impairments in spatial reversal learning and in contextual and cued memory. In addition, MK-801 produced hyperlocomotion, as has been observed in previous studies (Bardgett et al, 2003; Dall'Igna et al, 2003). Physostigmine and donepezil were both effective in 

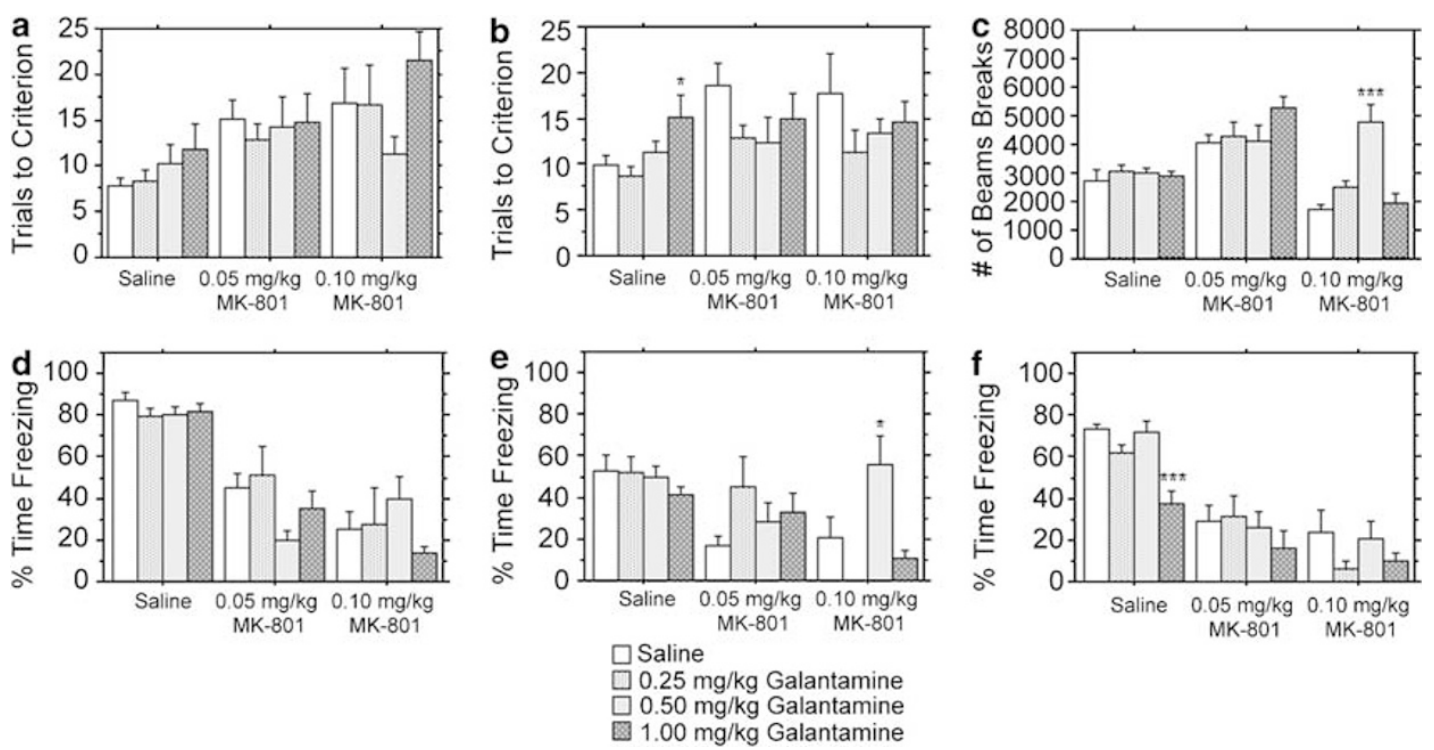

Figure 3 Effects of galantamine on changes in behavior induced by MK-80I in mice. One of three doses of galantamine were administered (s.c.) prior to administration of one of two doses of MK-80I in separate groups of mice ( $n=10-12$ per experimental group). Each panel represents the results of a different behavioral measure (see Figure I for panel descriptions). See the narrative for ANOVA results. Significant differences between individual groups pretreated with one of the three doses of galantamine prior to administration of saline or one of two doses of MK-80I as compared to the groups pretreated with saline prior to administration of saline or one of two doses of MK-80I are denoted by $* p<0.05$, *** $p<0.0$ I, or $* * * *<0.00$ I.

ameliorating the deficits in spatial reversal learning and in contextual and cued memory produced by MK-801 administration in a dose-dependent manner. In contrast, galantamine was not effective in ameliorating the behavioral deficits produced by MK-801 administration, and even appeared to further interfere with memory for the cue at the highest dose of galantamine tested $(1.0 \mathrm{mg} / \mathrm{kg})$. Further, physostigmine, but not donepezil, reversed the hyperlocomotion produced by MK-801. Finally, galantamine, but not physostigmine or donepezil, decreased sensitivity to the shock used in the fear-conditioning paradigm.

Although these findings suggest that at least two of the three AChE inhibitors tested had the capacity to ameliorate deficits in learning and memory produced by MK-801, MK801, and the AChE inhibitors might also have had nonspecific effects on behavior. For example, MK-801 produced decreases in freezing responses to the altered context in the fear-conditioning paradigm, and physostigmine and donepezil appeared to reverse this effect. While the altered context condition of the fear-conditioning paradigm was intended as a control condition not related to learning or memory, elements of the altered context may have been sufficiently similar to the context in which the fear conditioning took place so that memory for context was involved in the animals' responses. Also, MK-801 produced hyperlocomotion, which could have had an effect on the animals' performance in the spatial reversal learning paradigm. However, while both physostigmine and donepezil ameliorated the effects of MK-801 in the spatial reversal learning and fear-conditioning paradigms, only physostigmine reversed the hyperlocomotion produced by MK-801. Galantamine also produced small, but significant, increases in locomotion when administered alone and in combination with MK-801. Finally, physostigmine produced increases in freezing associated with the cue and alternate context even when administered in combination with saline. These findings suggest that the behavioral effects of the AChE inhibitors tested might have involved alterations in motor behavior that were unrelated to the actions of MK-801.

It should be kept in mind that the order of behavioral testing was predetermined rather than randomized to minimize interference between testing paradigms, which could have influenced the results. However, similar differences across the three AChE inhibitors were observed in spatial reversal learning and contextual and cued memory, which is not consistent with the presence of order effects. Also, it is possible that galantamine might have been effective at doses that were either higher or lower than the ones tested in this study. The highest dose of galantamine actually seemed to interfere with the capacity for cued memory, which may be related to the fact that modulators of nicotinic ACh receptors can interfere with Ach release at high doses (see below). Finally, the behavioral effects of MK-801 were not identical in the three separate experiments in which the capacity of physostigmine, donepezil, and galantamine to reverse the effects of MK801 was evaluated. In particular, the high dose of MK-801 had different effects on locomotion in the three experiments, and only in Experiment 3, where galantamine was evaluated, did MK-801 have an effect on shock sensitivity. However, the effects of MK-801 were highly similar and dose-dependent in the two major behavioral paradigms that were used to evaluate the cognition-enhancing effects of the AChE inhibitors.

Our findings that MK-801 produced impairments in performance in two behavioral paradigms related to learning and memory are consistent with previous studies 
examining the behavioral effects of noncompetitive NMDA receptor antagonists in rodents (Walker and Gold, 1992; Bardgett et al, 2003; Moghaddam and Jackson, 2003). While the circuitry underlying learning and memory in the mammalian brain remains under investigation, proper functioning of the NMDA receptor within the septohippocampal pathway appears to be a critical element of this circuitry (Newcomer and Krystal, 2001). Moreover, our findings that at least two of the three AChE inhibitors ameliorated the effects of NMDA receptor blockade are in keeping with earlier observations of the effects of physostigmine on cognitive impairments produced by the NMDA antagonist, NPC 12626 (Walker and Gold, 1992), as well as what is known about the interconnections between cholinergic neurons in the medial septum and excitatory glutamatergic circuits within the hippocampus. Cholinergic projections to the hippocampus generate and sustain the rhythmic activity of excitatory glutamatergic pathways within the hippocampus (Colgin et al, 2003), and development of new memory traces during encoding appears to be modulated by cholinergic input into specific hippocampal subregions. Also, NMDA receptors on GABA interneurons modulate acetylcholine release in the hippocampus and cortex (Giovannini et al, 1994; Kim et al, 1999). MK-801 has been reported to increase acetylcholine release in the hippocampus and cortex (Hutson and Hogg, 1996; Kim et al, 1999; Hasegawa et al, 1993), but not in the striatum (Hutson and Hogg, 1996) or the pontine reticular formation (Lydic and Baghdoyan, 2002). In a recent review, Gold (2004) noted that the influence of cholinergic mechanisms on learning and memory is complex, and that particular behaviors can be optimized by changing the levels of acetylcholine release in one structure relative to another, rather than by changing the absolute level of acetylcholine release throughout the brain.

Our finding that physostigmine and donepezil, but not galantamine, were effective in ameliorating the deficits in learning and memory produced by MK-801 raises the question of differences in the pharmacologyy of the three drugs. Galantamine is a weak inhibitor of AChE ( $\mathrm{IC}_{50}$ is in the $\mu \mathrm{M}$ range) as compared to some other AChE inhibitors (Samochocki et al, 2003). However, both galantamine and physostigmine act as allosteric modulators at the nicotinic acetylcholine receptor (Samochocki et al, 2003). At lower doses of such modulators, nicotinic receptors on the terminals of acetylcholine neurons are activated, intracellular calcium levels are increased, and neurotransmitter release is facilitated. However, at higher doses, nicotinic receptor function and neurotransmitter release can be inhibited (Samochocki et al, 2000). Considering these differences in the pharmacology of the three drugs, our findings suggest that the capacity of physostigmine and donepezil to ameliorate cognitive deficits produced by MK801 may be the result of AChE inhibition and increases in synaptic levels of $\mathrm{ACh}$, rather than allosteric modulation of the nicotinic acetylcholine receptor. In turn, however, increases in synaptic levels of ACh would increase the stimulation of both muscarinic and nicotinic ACh receptors, and direct stimulation of both subtypes of $\mathrm{ACh}$ receptors in the hippocampus has been shown to enhance memory (Kim and Levin, 1996). In future studies, it would be informative to determine whether direct stimulation of muscarinic or nicotinic $\mathrm{ACh}$ receptors can ameliorate deficits in learning and memory produced by MK- 801 .

There is increasing evidence that NMDA receptor hypofunction, in this study produced by noncompetitive receptor blockade, may be a useful model of the pathophysiology of schizophrenia. In addition to clinical studies showing that the administration of noncompetitive NMDA receptor antagonists can produce schizophrenia-like symptoms in humans (Goff and Coyle, 2001), there is evidence of abnormal NMDA receptor expression in the brains of subjects with schizophrenia (Coyle and Tsai, 2004). Recent work suggests the NMDA NR1 subunit mRNA is decreased in the CA3 while the NMDA NR2A subunit mRNA is increased in the CA2 of schizophrenics compared to controls (Gao et al, 2000). Also, increases in kynurenic acid, an endogenous antagonist at the glycine modulatory site on the NR1 subunit of the NMDA receptor, have been reported in numerous brain regions of subjects with schizophrenia, including the medial temporal lobe (Schwarcz et al, 2001). Thus, to the extent that MK-801induced blockade of the NMDA receptor can be interpreted as a pharmacological model of at least one element of the pathophysiology of schizophrenia, the results of this study may be useful for predicting which AChE inhibitors may be most effective for ameliorating the cognitive deficits associated with schizophrenia.

As mentioned in the Introduction, donepezil and galantamine have been preliminarily tested for their capacity to enhance cognition in patients with schizophrenia. In two open-label trials where donepezil was added to the ongoing treatment of schizophrenia subjects with atypical antipsychotic drugs, an improvement in manual dexterity (Buchanan et al, 2002) and in clinical measures of dementia (eg MMSE) (Stryjer et al, 2003) was observed. However, in double-blind studies of donepezil added to treatment with risperidone (Friedman et al, 2002) or clozapine (Stryjer et al, 2004), no beneficial effects were observed. Preliminary results with galantamine added to ongoing atypical antipsychotic drug treatment have been similarly inconclusive (Ochoa and Clark, 2004; Schubert et al, 2004). In addition, direct stimulation of both muscarinic (Shannon et al, 2000; Dean et al, 2003) and nicotinic (Martin et al, 2004) ACh receptors has been investigated as a means of enhancing cognition in patients with schizophrenia. Earlier concepts of the use of cholinomimetic drugs in schizophrenia focused on the potential of such drugs to relieve psychotic symptoms (Dean et al, 2003). Certainly, testing them for their specific effects on specific elements of cognition that might contribute to the complex presentation of schizophrenia is a refinement. However, given the expense of clinical trials of AChE inhibitors and other cholinomimetic drugs in combination with various antipsychotic drugs in patients with schizophrenia, further experimentation using animal models of cognition that may be analogous to the cognitive deficits of schizophrenia may be highly useful.

\section{ACKNOWLEDGEMENTS}

This research was supported by Public Health Service grant MH 60883. 


\section{REFERENCES}

Adler CM, Malhotra AK, Elman I, Goldberg T, Egan M, Pickar D et al (1999). Comparison of ketamine-induced thought disorder in healthy volunteers and thought disorder in schizophrenia. Am J Psychiatry 156: 1646-1649.

Aigner TG, Mishkin M (1986). The effects of physostigmine and scopolamine on recognition memory in monkeys. Behav Neural Biol 45: 81-87.

Allen RM, Young SJ (1978). Phencyclidine-induced psychosis. Am J Psychatry 135: 1081-1084.

Andine P, Widermark N, Axelsson R, Nyberg G, Olofsson U, Martensson E et al (1999). Characterization of MK-801-induced behavior as a putative rat model of psychosis. J Pharm Exp Ther 290: 1393-1408.

Ballard TM, McAllister KH (1999). The acetylcholinesterase inhibitor, ENA 713 (Exelon), attenuates the working memory impairment induced by scopolamine in an operant DNMTP task in rats. Psychopharmacology 146: 10-18.

Bardgett ME, Boeckman R, Krochmal D, Fernando H, Ahrens R, Csernansky JG (2003). NMDA receptor blockade and hippocampal neuronal loss impair fear conditioning and position habit reversal in C57Bl/6 mice. Brain Res Bull 60: 131-142.

Barnes CA, Meltzer J, Houston F, Orr G, McGann K, Wenk GL (2000). Chronic treatment of old rats with donepezil or galantamine: effects on memory, hippocampal plasticity and nicotinic receptors. Neuroscience 99: 17-23.

Benes FM (1999). Evidence for altered trisynaptic circutry in schizophrenic hippocampus. Biol Psychiatry 46: 589-599.

Buchanan RW, Summerfelt A, Tek C, Gold J (2002). An openlabeled trial of adjunctive donepezil for cognitive impairments in patients with schizophrenia. Schizophrenia Res 59: 29-33.

Buffalo EA, Gillam MP, Allen RR, Paule MG (1994). Acute behavioral effects of MK-801 in rhesus monkeys: assessment using an operant test battery. Pharma Biochem Beh 48: 935-940.

Colgin LL, Kubota D, Lynch G (2003). Cholinergic plasticity in the hippocampus. PNAS 100: 2872-2877.

Coyle JT, Tsai G (2004). NMDA receptor function, neuroplasticity, and the pathophysiology of schizophrenia. Intl Rev Neurobiol 59: 491-515.

Dall'Igna OP, Da Silva AL, Dietrich MO, Hoffman A, de Oliveira $\mathrm{RV}$, Souze DO et al (2003). Chronic treatment with caffeine blunts the hyperlocomotor but not the cognitive effects of the $\mathrm{N}$ methyl-D-asparate receptor antagonist MK-801 in mice. Psychopharmacology 166: 258-263.

Dean B, Bymaster FP, Scarr E (2003). Muscarinic receptors in schizophrenia. Curr Mol Med 3: 419-426.

Everitt BJ, Robbins TW (1997). Central cholinergic systems and cognition. Annu Rev Psychol 48: 649-684.

Fenton W, Stover EL, Insel TR (2003). Breaking the log-jam in treatment development for cognition in schizophrenia. Psychopharmacology 169: 365-366.

Freedman R, Hall M, Adler LE, Leonard S (1995). Evidence in postmortem brain tissue for decreased numbers of hippocampal nicotinic receptors in schizophrenia. Biol Psychiatry 38: 22-33.

Friedman JI (2004). Cholinergic targets for cognitive enhancement in schizophrenia: Focus on cholinesterase inhibitors and muscarinic agonists. Psychopharmacology 174: 45-53.

Friedman JI, Adler DN, Howanitz E, Harvey PD, Brenner G, Temporini $\mathrm{H}$ et al (2002). A double blind placebo controlled trial of donepezil adjunctive treatement to risperidone for the cognitive impairment of schizophrenia. Biol Psychiatry 51: 349-357.

Gao X-M, Sakai K, Roberts RC, Conley RR, Dean B, Tamminga CA (2000). Ionotropic glutamate receptors and expression of $N$ methyl-D-aspartate receptor subunits in subregions of human hippocampus: effects of schizophrenia. Am J Psychiatry 157: $1141-1149$.
Giovannini MG, Mutolo D, Bianchi L, Michelassi A, Pepeu G (1994). NMDA receptor antagonists decrease GABA outflow from the septum and increse acetylcholine outflow from the hippocampus: a microdialysis study. J Neurosci 14: 1358-1365.

Goff DC, Coyle JT (2001). The emerging role of glutamate in the pathophysiology and treatment of schizophrenia. Am J Psychiatry 158: 1367-1377.

Gold PE (2004). Coordination of multiple memory systems. Neurobiol Learn Mem 82: 230-242.

Hasegawa M, Kinoshita M, Amano M, Hasegawa T, Kameyama T, Nabeshima T (1993). MK-801 increases endogenous acetylcholine release in the rat parietal cortex: a study using brain microdialysis. Neurosci Lett 150: 53-56.

Higgins GA, Enderlin M, Fimbel R, Haman M, Grottick AJ, Soriano $\mathrm{M}$ et al (2002). Donepezil reverses a mnemonic deficit produced by scopolamine but not by perforant path lesions or transient cerebral ischaemia. Eur J Neurosci 15: 1827-1840.

Hutson PH, Hogg JE (1996). Effects of and interaction between antagonists for different sites on the NMDA receptor complex on hippocampal and striatal acetylcholine efflux in vivo. Eur $J$ Pharmacol 295: 45-52.

Hyde TM, Crook JM (2001). Cholinergic systems and schizophrenia: primary pathology or epiphenomena? J Chem Neuroanat 22: 53-63.

Jian-ping J, Jian-min J, Wei-dong Z, Min X, Chang-biao C, Xin Y et al (2004). Differential acetylcholine and choline concentrations in the cerebrospinal fluid of patients with Alzheimer's disease and vascular dementia. Chin Med J 117: 1161-1164.

Kim JS, Levin ED (1996). Nicotinic, muscarinic and dopaminergic actions in the ventral hippocampus and the nucleus accumbens: effects on spatial working memory in rats. Brain Res 725: 231-240.

Kim SH, Price MT, Olney JW, Farber NB (1999). Excessive cerebrocortical release of acetylcholine induced by NMDA antagonists is reduced by GABAergic and $\alpha 2$-adrenergic agonists. Mol Psychiatry 4: 344-352.

Knopman D, Morris JC (1997). An update on primary drug therapies for Alzheimer's disease. Arch Neurol 54: 1406-1409.

Lenzi A, Maltinti E, Poggi E, Fabrizio L, Coli E (2003). Effects of rivastigmine on cognitive function and quality of life in patients with schizophrenia. Clin Neuropharmacol 26: 317-321.

Luisada PV, Brown BL (1976). Clinical management of the phencyclidine psychosis. Clin Toxicol 9: 539-545.

Lydic R, Baghdoyan HA (2002). Ketamine and MK-801 decreases acetylcholine release in the pontine reticular formation, slow breathing, and disrupt sleep. Sleep 25: 617-622.

Martin LF, Kem WR, Freedman R (2004). Alpha-7 nicotinic receptor agonists: potential new candidates for the treatment of schizophrenia. Psychopharmacology 174: 54-64.

Mesulam MM, Geula C (1988). Acetylcholinestase-rich pyramidal neurons in the human neocortex and hippocampus: absence at birth, development during the life span, and dissolution in Alzheimer's disease. Ann Neurol 24: 765-773.

Moghaddam B, Jackson ME (2003). Glutamatergic animal models of schizophrenia. Ann NY Acad Sci 1003: 131-137.

Newcomer JW, Krystal JH (2001). NMDA receptor regulation of memory and behavior in humans. Hippocampus 11: 529-542.

Ochoa ELM, Clark E (2004). Galantamine as an adjuvant treatment for negative symptoms in schizophrenia: a pilot study. Abstract Viewer/Itinerary Planner. Society for Neuroscience: Washington, DC. Program No. 351.8.

Ohno M, Kishi A, Watanabe S (1996). Effect of cholinergic activation by physostigmine on working memory failure caused in rats by pharmacological manipulation of hippocampal glutamatergic and 5-HTergic neurotransmission. Neurosci Lett 217: 21-24.

Olney JW, Farber NB (1995). Glutamate receptor dysfunction and schizophrenia. Arch Gen Psychiatry 52: 998-1007. 
Pepeu G, Giovannini MG (2004). Changes in acetylcholine extracellular levels during cognitive processes. Learn Mem 11: 21-27.

Raskind SL, Peskind ER, Wessel T, Yuan W (2000). Galantamine in AD: a 6-month, randomized, placebo-controlled trial with a 6-month extension. Neurology 54: 2261-2268.

Rogers JL, Kesner RP (2003). Cholinergic modulation of the hippocampus during encoding and retrieval. Neurobiol Learn Memory 80: 332-342.

Rogers JL, Kesner RP (2004). Cholinergic modulation of the hippocampus during encoding and retrieval of tone/shockinduced fear conditioning. Learning Memory 11: 102-107.

Rogers SL, Friedhoff LT and the Donepezil Study Group (1996). The efficacy and safety of donepezil in patients with Alzheimer's disease: results of a US multicenter, randomized double-blind, placebo-controlled trial. Dementia 7: 293-303.

Rupniak NM, Tye SJ, Field MJ (1997). Enhanced performance of spatial and visual recognition memory tasks by the selective acetylcholinesterase inhibitor E2020 in rhesus monkeys. Psychopharmacology 131: 406-410.

Samochocki M, Hoffle A, Fehrenbacher A, Jostock R, Ludwig J, Christner C et al (2003). Galantamine is an allosterically potentiating ligand of neuronal nicotinic but not of muscarinic acetylcholine receptors. J Pharm Exp Ther 305: 1024-1036.

Samochocki M, Zerlin M, Jostock R, Kormelink PJG, Luyten WHML (2000). Galantamine is an allosterically potentiating ligand of the human $\alpha 4 \beta 2$ nAChR. Acta Neurol Scand 176: 68-73.

Schubert MH, Young KA, Hicks PB (2004). Cognitive improvement in schizophrenia and schizoaffective disorder by augmentation of risperidone with galantamine. Abstract Viewer/Itinerary
Planner. Society for Neuroscience: Washington, DC. Program No. 351.10.

Schwarcz R, Rassoulpour A, Wu HQ, Medoff D, Tamminga CA, Roberts RC (2001). Increased cortical kynurenate content in schizophrenia. Biol Psychiatry 50: 521-530.

Shannon HE, Rasmussen K, Bymaster FP, Hart JC, Peters SC, Swedberg MDB et al (2000). Xanomeline, an M1/M4 preferring muscarinic receptor agonist, produces antipsychotic-like activitiy in rats and mice. Schizophrenia Res 42: 249-259.

Stewart M, Fox SE (1990). Do septal neurons pace the hippocampal theta rhythm? Trends Neurosci 13: 163-168.

Stryjer R, Strous RD, Bar F, Werber F, Shaked G, Buhiri Y et al (2003). Beneficial effect of donepezil augmentation for the management of comorbid schizophrenia and dementia. Clin Neuropharmacol 26: 12-17.

Stryjer R, Strous R, Bar F, Shaked G, Shiloh R, Rozencwaig S et al (2004). Donepezil augmentation of colzaine monotherapy in schizophrenia patients: a double blind cross-over study. Hum Psychopharmacol 5: 343-346.

Tugal O, Yazici KM, Yagcioglu AE, Gogus A (2004). A double blind, placebo controlled, cross over trial of adjunctive donepezil for cognitive impairment in schizophrenia. Int J Neuropsychopharmacol 7: 117-123.

Walker DL, Gold PE (1992). Impairment of spontaneous alternation performance by an NMDA antagonist: attenuation with non-NMDA treatments. Behav Neural Biol 58: 61-69.

Wang T, Tang XC (1998). Reversal of scopolamine-induced deficits in radial arm maze performance by (-)-huperzine A: comparison with E2020 and tacrine. Eur J Pharmacol 349: 137-142. 